\title{
Libro: Estado y sector lácteo. Historia reciente de la construcción de políticas públicas: Argentina, 1983-2008
}

María Elena Nogueira

Prohistoria Ediciones, Rosario, 2011 (220 pp.)

\author{
Marcos Urcola \\ Investigador asistente del Consejo Nacional de Investigaciones Científicas y Técnicas y \\ docente de la Universidad Nacional de Rosario, Argentina. \\ E-mail: murcola@hotmail.com
}

Las tensiones en torno del precio que se paga por el crudo de leche y el precio final del litro de leche y sus derivados en las góndolas de los supermercados, forma parte de un problema crónico del sector agropecuario que, en palabras de los propios actores, "se repite cada tres o cuatro años" y que fue el antecedente sectorial más próximo al generado por las retenciones móviles en 2008. El 1 de abril de 2012, el titular de un artículo del diario La Capital de Rosario sentenciaba: La guerra de la leche inauguró el año de conflictos agropecuarios. A partir de ese momento, pudimos asistir a un "nuevo round para un viejo conflicto" del sector lácteo en torno al precio de la leche que se prolongó durante todo el año y tuvo su momento más álgido durante el mes de agosto con cortes de rutas, derrame de leche y bloqueos de más de treinta usinas de las provincias de Santa Fe y Córdoba por parte de los tamberos. La cantidad de declaraciones cruzadas plasmadas en los distintos medios gráficos y audiovisuales por parte de la heterogénea cantidad de actores intervinientes en el conflicto, nos advierte sobre la complejidad de una cadena productiva comprendida por productores de leche fluida, empresarios de la industria láctea y de supermercados, diferentes estamentos del Estados nacional, los Estados provinciales y los propios consumidores. A partir de esto puede observarse que las dificultades de este histórico conflicto no radican sólo en las tensiones que se generan entre los diferentes eslabones de la cadena, sino en la complejidad interna de las organizaciones representativas de cada uno de ellos (principalmente del sector primario) y en el hecho de que los productos lácteos representan bienes de suma importancia en la canasta básica de alimentos de los hogares de nuestro país.

Teniendo presente este último episodio de disputa sectorial, resulta pertinente sugerir a aquella persona interesada en trascender el análisis coyuntural, la lectura del trabajo elaborado por María Elena Nogueira en el marco de sus estudios doctorales en Ciencia Política sobre Estado y sector lácteo. En el mismo, la autora aborda detalladamente la relación entre los agentes productivos y comerciales del 
sector lácteo y el Estado a partir del análisis de las políticas públicas y sus procesos constitutivos desde la óptica de la concertación social.

A partir del supuesto de que los procesos de concertación en políticas públicas contribuyen a mejorar la calidad democrática de las instituciones políticas de nuestro país, Nogueira se propone "describir y explicar el ingreso y tratamiento en la agenda pública de la problemática del sector lácteo y su incidencia en el proceso de resolución de ésta a través de intentos de concertación" (p. 175). Para ello, indaga sobre la relación entre la formación de agenda de gobierno en torno a la "cuestión láctea" y el rol de los diferentes agentes sectoriales desde una perspectiva neocorporatista.

La autora plantea como hipótesis que la forma de ingreso de la cuestión láctea como problema de agenda es una variable relevante para la comprensión de los procesos de concertación sectorial o, como en el caso argentino, para explicar sus fracasos. Si bien considera las capacidades estatales y las formas que toma la movilización y organización sectorial como variables importantes, el problema lácteo argentino y sus sucesivos intentos de concertación truncos, no parecieran poder explicarse sólo a partir de éstas y de allí la relevancia que cobran los procesos de construcción de agenda y los contextos que la rodean. "La ineficiencia de los instrumentos de políticas y la pasividad del sector una vez obtenido un resultado favorable en el corto plazo actúan como elementos contingentes ante las soluciones concertadas que se ensayan y, en términos teóricos, pueden entenderse como fallas en prácticas de raíz neocorporatista" (p. 23).

Con una metodología preferentemente cualitativa, la investigación se encuentra ampliamente documentada a partir de la selección y análisis de periódicos y revistas especializadas, documentos oficiales, leyes, actas de sesiones del Congreso y entrevistas en profundidad a referentes claves del Estado (nacional y provincial) y actores corporativos y no corporativos que representan al sector (productores primarios, industriales, de comercialización, etc.). El estudio se sitúa en un espacio temporal significativo de nuestra historia democrática reciente como es el período que va desde el año 1983 hasta el 2008 y, si bien circunscribe su análisis a todo el territorio nacional, hace especial mención al caso de la provincia de Santa Fe por la gran cantidad de entidades sectoriales y de agencias de gobierno que dicha provincia presenta en las mesas de diálogo.

Para el estudio de las variables propuestas (capacidades estatales, actores sectoriales y agenda pública) dentro del período 1983-2008, Nogueira diferencia tres etapas que se relacionan con los contextos estructurales de creación de políticas macroeconómicas (o regímenes sociales de acumulación) y con características particulares de la política láctea nacional. Entre los factores contextuales que hacen a la formación de agenda, la autora distingue aquellos independientes del sector (o exógenos), tales como la devaluación de la moneda brasilera a fines de 1990, la sequía de 2007-2008, la rentabilidad de la soja como alternativa al tambo, entre otros; y aquellos que son propios del sector (endógenos), como las transformaciones institucionales en el interior de la Secretaría de Agricultura, Ganadería, Pesca y Alimentación (SAGPyA), la fragmentación de los actores sociales que se 
disputan la representación sectorial, la ausencia de actores relevantes en las mesas de diálogo (como las grandes cadenas de supermercados), etc. Tales elementos varían en su peso e importancia en cada una de las etapas analizadas.

1) El período 1983-1990 se establece como el referente más claro en cuanto a los intentos de concertación de políticas del sector lácteo con la creación de algunos instrumentos destacables como la Comisión para la Concertación de Políticas Lecheras (COCOPOLE) y el Fondo para la Actividad Láctea (FOPAL) en un contexto de alta inestabilidad económica ("hiperinflación") y política (intentos de golpe de Estado), con precios internacionales y locales bajos, sobreoferta de materias primas, dispersión de la representación sectorial y debilidad de los mecanismos de concertación, entre otros.

2) El período 1991-2001 se caracteriza por el desmantelamiento del Estado, que delega su rol protagónico en el mercado y, en última instancia, en los gobiernos provinciales. Se desarman los instrumentos de concertación antes mencionados y se limitan el rol de las agencias ligadas al sector agropecuario a tareas técnicas y de apoyo a la producción. El denominado Plan de Convertibilidad (que dispuso la paridad peso-dólar) marca un contexto macroeconómico y sectorial notoriamente diferente al de la década anterior. El mismo es denominado por la autora como de crecimiento/exclusión, puesto que se trata de un contexto que garantiza crecimiento y rentabilidad a partir del aumento de las exportaciones y la recomposición del consumo interno, pero, a la vez, genera la salida de la actividad de un número significativo de productores y pequeñas industrias sin escala o con alto endeudamiento.

3) El período 2002-2008 se caracteriza por la dramática salida de la convertibilidad y posterior devaluación con un reposicionamiento del Estado en algunas áreas. En 2002 se destaca la creación del Programa Nacional de Política Leche$r a$ (PNPL) y algunos espacios de concertación a nivel nacional y provincial que resultan novedosos, tales como el "Acta compromiso de buenas prácticas para la operatoria comercial láctea" (2004), el "Programa de Apoyo Tambero" (2006) y el "Programa de Estabilización de Precios de Productos del Sector Lácteo destinados al Mercado Interno" (2007). El contexto de este período es similar al del período 1983-1990, con precios internacionales y locales bajos, mayor dispersión de la representación sectorial (a partir de la aparición de nuevas organizaciones del sector), debilidad de las capacidades estatales, contingencias climáticas y preferencia por la producción sojera.

En esta última etapa, la autora señala que la cuestión láctea se considera un eje estratégico de la SAGPyA (actual Ministerio de Agricultura Ganadería y Pesca), creándose como novedad una Dirección Nacional de Lechería. No obstante, la forma de construcción de las políticas públicas pondría al Estado en condiciones de debilidad frente al tratamiento de la cuestión, reduciendo sus capacidades en la coordinación de las políticas y en el peso determinante que se requeriría del mismo dentro de este complejo institucional. Es posible visualizar un gran despliegue en cuanto a los espacios de diálogo, pero éstos han tenido pocos resultados en términos de instrumentos de política. Se llega a organizar una agenda sectorial, 
pero su tratamiento se delega en forma casi total en las organizaciones del sector que, a su vez, encuentran serias dificultades en lograr acuerdos, especialmente en la fase primaria de la cadena. "Los actores sectoriales reflexionan la política sin el Estado y éste, a su vez, aguarda con sosiego la propuesta sobre la que tomará la decisión" (p. 170).

Precisamente, la complejización del mapa asociativo que se conforma a partir de 2002-2003, es uno de los puntos interesantes que describe muy detalladamente este estudio, indicando el aumento en la dispersión de la representación sectorial en la fase agraria o primaria del complejo, donde convergen la asociaciones tradicionales, como Federación Agraria o la Sociedad Rural, y las nuevas, como las cámaras por producto o las mesas de lechería cuyo accionar se inscribe muchas veces dentro de la lógica de los movimientos sociales. Sumado a esto, otro aspecto relevante dentro de este último período es el rol relevante que han asumido los gobiernos provinciales que genera cierta "provincialización" o regionalización de la agenda. Según la autora, esta representación ampliamente pluralista y considerablemente heterogénea no garantiza una democratización de los espacios de diálogo, sino que, por el contrario, su gran dispersión y tensiones internas tienden a obstaculizar la construcción de consensos.

Teniendo en cuenta la relación entre capacidades estatales, actores sectoriales y agenda pública en los tres períodos, Nogueira destaca a la etapa 1983-1990 como un momento de concertación trunca con capacidades estatales débiles, actores sectoriales con capacidad de presión y agenda de emergencia; a la etapa 19912001 como un período de concertación pasiva con capacidades estatales débiles, actores sectoriales desplazados de la arena política y agendas pasivas o de "dejar hacer"; y, finalmente, a la etapa 2002-2008 como la de mayor dinamismo donde, a pesar de sus complejidades y paradojas, se observan agendas activas en cuanto a la construcción social que inscribe la cuestión láctea en el terreno de la política, con alta visibilidad de los actores sectoriales y capacidades estatales aún débiles que deriva en un proceso de concertación latente.

Como denominador común del análisis de estos períodos se detecta la existencia de contextos sectoriales de emergencia ligados a bajos precios y pérdida de rentabilidad (principalmente en los períodos 1983-1990 y 2002-2008) que actúan como principales condicionantes del tratamiento en la agenda y de los resultados negativos respectos del diseño de política pública concertada.

El análisis que atraviesa el estudio demuestra que la cuestión láctea ingresa en agenda de gobierno sólo en momentos de crisis y no logra ser visualizada como una temática relevante para el desarrollo de una política de largo plazo que trascienda la emergencia y la coyuntura por la disputa en torno al precio de la leche. En palabras de la autora, "la forma ocasional o de emergencia en la que la problemática láctea ingresa en la agenda pública a lo largo del período de análisis contribuye a generar, la mayor parte de las veces, procesos de concertación sectorial truncos que coinciden, por un lado, con un conjunto de debilidades en las formas de organización sectorial y, por otro, con coyunturas críticas para la actividad" (p. 23). 
Estado y sector lácteo es un estudio que brinda herramientas plenamente vigentes para la interpretación de los conflictos que perduran hasta hoy. La forma de ingreso en agenda que denota el episodio de 2012 por el detonante del precio de la leche fluida ${ }^{1}$, la debilidad de las agencias del Estado para conducir el proceso de diálogo en forma exitosa y la compleja red de actores que se disputan la representación sectorial con múltiples fracturas ${ }^{2}$, dan plena vigencia al estudio de Nogueira para el análisis de la actualidad del sector y nos invita a reflexionar como mayor claridad sobre este tipo de fenómenos que se presentan como un déjà $v u$ de nuestra historia nacional.

Para salir de esta trama reiterativa de experiencias de concertación fallidas, la autora sugiere la necesaria recuperación de las capacidades y el rol del Estado como factor clave que permita conectar los momentos en que la cuestión láctea adquiere importancia y lo que sucede después en términos de elaboración de políticas públicas. Como bien indica en las conclusiones de su estudio, "el sutil equilibrio en la relación entre el Estado y los actores sectoriales para que las políticas sean verdaderas construcciones democráticas parece ser la pieza clave en el rompecabezas que invitan a armar los procesos de elaboración de políticas públicas en contextos democráticos (...). El Estado, tiene una responsabilidad de actuación en estos ámbitos que no sólo no puede eludir sino que debe reafirmar y fortalecer en su fin último de tender a garantizar el bien común en el marco de un régimen democrático" (p. 182).

\section{Referencias}

1. Ver "Los tamberos reclaman aumento del precio de la leche que está congelado en 1,45 pesos", $L a$ Capital, 28 de marzo de 2012.

2. Ver "Tras el acuerdo en el conflicto lechero, se fracturó el frente", La Capital, 10 de agosto de 2012. 